\title{
A MISCELÂNEA NAS TEORIAS DE ADMINISTRAÇÃO HAROLD KOONTZ
}

\begin{abstract}
“A teoria da administração ề, na sua essência, a teoria da racionalidade intencional e linitada do comportamento de sêres humanos que contemporizam porque não possuem meios para maximinizar." -
\end{abstract}

Herbert A. Simon

Embora os estudiosos de Administração estejam dispostos a concordar em que problemas administrativos existem desde os primórdios da vida organizada, a maioria dêles também concordaria em que um exame sistemático dos fenômenos administrativos, salvo raras exceções, é produto do nosso século e, mais especificamente, dos dois últimos decênios. Além do mais, até há bem pouco tempo, todos aquêles que tentavam analisar os processos administrativos e se entregavam à procura de algum fundamento para auxiliar o desenvolvimento da pesquisa, bem como o ensino e a prática da Administração, eram pessoas atentas e sensíveis a uma arte originária de longos anos de experiências. Conseqüentemente, pelo menos em se considerando a Administração como arte intelectualmente fundamentada, as primeiras obras importantes foram escritas por práticos em administração, como FAYOL, MoONeY, Alvin, Brown, Sheldon, Barnard e URWick. Com certeza, nem mesmo os mais acadêmicos cul-

\footnotetext{
Harold KoontZ - Prcfessor de Diretrizes e Transportes da "Graduate School of Business Administration" da Universidade da Califórnia.

NOTA DA REDAçÃo: Artigo reproduzido com autorizaçãc da "The Journal of the Academy of Management", onde foi publicado em dezembro de 1961, volume $4, n .^{\circ} 3$. Traduzido do inglês por CarLos Osmar BERTERo.
} 
tores da pesquisa experimental poderão prescindir do empirismo implícito na tentativa de extrair princípios fundamentais a partir de experiências observadas, como o fizeram os administradores práticos que acabam de ser mencionados. Conquanto as primeiras elaborações tenham sido formuladas propositadamente sem a aplicação de questionários, sem entrevistas controladas e sem o uso de recursos matemáticos, não é exato que elas tenham sido apriorísticas ou concebidas em "tôrres de marfim".

Merece atenção o fato de que escritos e pesquisas acadêmicos estejam ausentes nos anos de formação das teorias modernas de Administração, em contraste com os nossos dias, quando somos afogados num verdadeiro dilúvio de pesquisas e escritos realizados nas universidades. É interessante - e talvez não constitua mais do que um sintoma da adolescência sofisticada da Teoria Administrativa - o processo pelo qual a inundação acadêmica trouxe consigo uma onda de grandes diferenças e de aparente confusão. Em lugar da análise ordenada da administração ao nível industrial (como a desenvolvida por FREDERI $=\mathrm{K}$ W. TAYLOR) ou da destilação reflexiva de experiências segundo os interêsses da alta administração (como foi o caso de Henry Fayor), assistimos agora a um crescimento desordenado, ao emaranhado de uma verdadeira floresta de opiniões de intelectuais que procuram dar aos problemas teóricos da administração as mais diversas formas de tratamento.

Há os "behavioristas" - influenciados pelos experimentos da Hawthorne e pelo interêsse despertado pelas Relações Humanas durante as décadas de 1930 e 1940 - que vêem a administração como um complexo de relações interpessoais e encontram base para uma teoria de administração nas afirmações provisórias de uma ciência pouco desenvolvida como a Psicologia. Existem também os que vêem a Teoria Administrativa como simples manifestação dos fenômenos culturais e institucionais objeto da Sociologia. Há ainda outros que, ao notar que o cerne da administração é o processo decisório, partem daí para ten- 
tar englobar nesse processo tudo o que existe dentro da estrutura orgânica de uma emprêsa. Então aparecem os matemáticos, que pensam seja a administração, antes de mais nada, um exercício de relações lógicas que se exprimem em símbolos, de conformidade com um onipresente e sempre reverenciado modêlo. Mas, o entrelaçamento dêsse crescimento atinge o seu clímax quando o estudo da administração é visto como o estudo de um dentre vários sistemas e subsistemas, o que torna o pesquisador insatisfeito enquanto não consegue abranger todo o universo físico e cultural como um grande sistema administrativo!

Com as recentes descobertas de vastíssimas áreas de investigação e de problemas até o momento insolúveis tarefa realizada por sociólogos, físicos e biólogos - e com o aumento supersônico do interêsse por essas descobertas, por parte de todos os tipos de administradores, a aparente inexpugnabilidade da hoje chamada Teoria Administrativa não é de difícil compreensão. Não mais estranha que psicólogos, sociólogos, antropólogos, sociometristas, economistas, matemáticos, físicos, biólogos, cientistas políticos, intelectuais dedicados à especulação no campo da administração empresária e até mesmo administradores práticos devam competir nessa prova tão interessante, estimulante e lucrativa.

Êsse aumento de interêsse, oriundo de todos os setores da vida intelectual e administrativa, não deve causar preocupações a ninguém que esteja desejoso de ver definidas as fronteiras do conhecimento e ampliada a base intelectual da prática administrativa. Mas, o que se tornou motivo de real preocupação para o administrador prático e para o observador que vislumbre o poderio social que uma administração aperfeiçoada pode proporcionar é o fato de a variedade do tratamento dado à Teoria Administrativa ter provocado uma espécie de "guerra fria" meramente destrutiva. Especialmente entre as várias disciplinas acadêmicas e entre os seus respectivos discípulos, os interêsses fundamentais dos pretensos líderes parece 
consistir em simplesmente inventar um tratamento "original" da problematicidade administrativa. E para defender a sua originalidade e, dessa forma, ganhar um ingresso para a posteridade (ou, pelo menos, conseguir publicar algo que justifique o seu status acadêmico ou a sua promoção) tornou-se prática corrente menosprezar e, por vêzes, deturpar o que os outros disseram, pensaram ou fizeram .

Procurando penetrar nessa floresta e tornar claros alguns pontos importantes e alguns problemas existentes na Teoria da Administração em nossos dias, para que o grande interêsse, a inteligência e os resultados das pesquisas possam adquirir mais sentido, procurei classificar as várias "escolas" de Teoria Administrativa. Tentarei identificar ràpidamente o que creio ser a principal fonte das diferenças e oferecer algumas sugestões para abrir clareiras na floresta. Espero com isso contribuir para que pelo menos aquêles que estiverem na referida área de interêsse não sejam censurados por estarem a chamar a mesma coisa pelos mais variados nomes, abusando de uma terminologia demasiado ampla e atribuindo às teses uma argumentação viciada.

\section{AS PRINCIPAIS "ESCOLAS" DE TEORIA ADMINISTRATIVA}

$\mathrm{Na}$ tentativa de classificar as principais escolas de Teoria Administrativa em seis grupos básicos, estou ciente de poder subestimar alguns aspectos, porquanto não será possível tratar de tôdas as caraterísticas de cada escola. Parece-me, contudo, que a maioria dos tratamentos até hoje dados à Teoria Administrativa pode ser adequadamente classificada nos seis grupos que a seguir serão discriminados.

\section{A Escola do Processo Administrativo}

Essa escola vê a administração como um processo de realizar coisas por meio de pessoas que operam dentro de grupos organizados. Ela cuida, porisso, de analisar o processo, estabelecer um quadro conceitual para entendimen- 
to do processo, identificar os princípios subjacentes ao processo e elaborar uma teoria administrativa baseada nesses princípios. Considerando a admınıstração como um processo universalmente válido, embora reconhecendo que o ambiente administrativo difere amplamente entre os vários tipos de emprêsa e entre os vários níveis de u'a mesma emprêsa, essa escola entende a Teoria Administrativa com uma forma de organizar a experiência para que a prática possa ser melhorada mediante pesquisas, verificação experimental dos princípios e ensino dos fundamentos do processo administrativo. ${ }^{1}$

Freqüentemente chamada, especialmente pelos seus críticos, de "tradicional" ou "universalista", tem suas origens nas teorias de HENRY FAYOL, embora muitos dos seguidores tenham ignorado o fundador, pelo fato de a obra de FAYOL ter sido eclipada pelo brilho de seu contemporâneo FREDERICK TAYLOR, e pela falta de uma tradução inglêsa, necessidade só satisfeita tardiamente em 1949. Além de FAyol, a maioria dos primeiros contribuidores dessa escola trataram apenas da parte orgânica do processo administrativo, em razão de sua maior experiência nesse campo da administração e também pelo fato de que o planejamento, o contrôle e a função de assessoria mereciam pouca atenção dos administradores até 1940 .

A Escola do Processo Administrativo baseia sua concepção da Teoria Administrativa em várias proposições:

1) a administração é um processo que pode ser dissecado intelectualmente pela análise das funções do administrador;

1) Recentemente um estudioso (orientado no sentido das Relações Humanas e do tratamento comportamentista da problematicidade administrativa) observou que a Teoria Administrativa "pode ser vista como uma forma de organizar a experiência" e que, "uma vez captado o sentido da experiência ambiente, abre-se o caminho para uma organização ainda mais adequada dessa experiência". Veja-se, a propósito: RoBERT DUBIN, in "Psyche, Sensitivity and Social Structure", comentário crítico de RoBERT TanNenbaum, I. R. Weschler e Fred Massarik, Leadership and Organization - A Behavioral Science Approach, Nova Iorque: McGrawHill Book, Co., 1961, pág. 401. 
2) uma longa vivência administrativa numa grande variedade de situações pode servir de base para a percepção de certas verdades fundamentais ou generalizações - habitualmente chamadas princípios - que ajudam a esclarecer e prever o entendimento e aprimoramento do ato de administrar;

3) êsses princípios podem tornar-se pontos básicos para uma pesquisa destinada a verificar a própria validade dêles, bem como a esclarecer o seu sentido e sua aplicabilidade;

4) êsses princípios, enquanto não contestados, podem fornecer elementos para a formação de uma teoria administrativa, sendo ainda passíveis de uma elaboração maior:

5) a Administração é uma arte que, à semelhança da Engenharia e da Medicina, pode ser aprimorada pela compreensão e utilização de princípios;

6) os princípios de Administração, assim como os princípios das ciências físicas e biológicas, não deixam de ser verdadeiros mesmo quando ignorados por determinado tratamento (digamos que a elaboração feita por um prático em dada situação ignore o princípio dos custos envolvidos ou tente fazer algo insólito para contrabalançar os custos incorridos), o que, evidentemente, não é novidade nos terrenos da Medicina, da Engenharia ou de qualquer outra arte, porque a arte tem tarefa criadora de tornar flexíveis os princípios a fim de atingir os resultados dese jados; e

7) como a cultura e os universos físico e biológico têm efeitos variáveis sôbre o ambiente em que o administrador e seus subordinados estejam localizados, como aliás acontece no campo de qualquer ciência ou arte, a Teoria Administrativa não tem necessidade de engiobar todo o conhecimento para fundamentar-se teórica e cientìficamente.

Para essa escola, portanto, o bàsicamente importante é considerar, em primeiro lugar, as funções dos administradores. Como numa segunda etapa dêsse procedimento 
muitos dentre nós posteriormente procuramos dissecar as funções administrativas com base no que julgávamos verdades fundamentais que haviamos captado do complexo fluxo das práticas administrativas, julguei útil classificar minha análise dessas funções em tôrno das seguintes questões essenciais:

1) Qual a natureza de uma função?

2) Qual o objetivo de uma função?

3) Como explicar a estrutura de uma função?

4) Como explicar o processo de uma função?

Talvez existam outras indagações mais úteis, mas, a meu ver, tudo o que pertence à área da Administração (inclusive alguns dos conceitos e pesquisas mais remotos) pode ser situado nesses quatro itens.

Por outro lado, a fim de tornar a área da Teoria Adminitrativa mais maleável intelectualmente, aquêles que se filiam a essa escola não tentam habitualmente incluir na Teoria, pelo menos de maneira integral, a Sociologia, a Economia, a Psicologia, a Biologia, a Física, a Química ou outras disciplinas. Não porque se considerem essas outras áreas do conhecimento desprovidas de importância ou alheias à Administração, mas simplesmente porque nunca houve um real progresso na ciência ou nas artes semi uma especialização substancial do conhecimento. Todavia, ninguém seria suficientemente tolo para ignorar que uma função que lida com pessoas nas suas várias atividades de produzir e mercadizar algo - desde o dinheiro até à religião e à educação - seja completamente independente dos universos físico, biológico e cultural em que vive. E não existem, porventura, tais relações de interdependência em outros ramos do conhecimento?

\section{A Escola Empirica}

A segunda escola eu a chamo "empírica". Nela incluo os pensadores que identificam a Administração com um estudo da experiência, por vêzes com vistas à elaboração de 
generalizações, mas habitualmente apenas como um meio de transmitir pelo ensino essa experiência ao administrador prático ou ao estudante. Seu objeto típico é o entendimento das diretrizes administrativas pelo estúdo e análise de casos e pela aplicação de recursos outros, tais como o "método comparativo" de ERNest Dale." E a premissa em que se baseia é a seguinte: o estudo das experiências de administradores bem sucedidos e dos erros que se praticam na administração, e o exercício de tentativas no sentido de solucionar problemas administrativos resultam na compreensão e na aprendizagem das técnicas administrativas mais eficazes. Supõe-se, como se vê, que a simples descoberta, pelo estudante ou pelo homem que se encontra na prática da administração, daquilo que tenha funcionado e daquilo que não tenha funcionado em circunstâncias individuais torná-los-á capazes de repetir as experiências bem sucedidas em situações comparáveis às anteriormente estudadas.

Não é possível negar a importância de adquirir conhecimento de experiências por êsse método de estudo ou por meio da análise do "como foi feito". Mas a Administra" ção, diversamente do Direito, não é uma ciência baseada em precedentes, onde as situações futuras quase sempre se repetem nos mesmos moldes do passado. Em Administração é perigoso confiar demasiadamente na experiência do passado e num histórico não filtrado das soluções de problemas administrativos, porque uma técnica julgada correta para o passado pode não corresponder satisfatòriamente a uma situação futura.

Os partidários da Escola Empírica possivelmente afirmarão que aquilo que fazem ao analisar um caso ou a história de emprêsas é tentar obter algumas generalizações que possam ser aplicadas como guias úteis para o pensamento e para a ação em situações futuras. De fato, ERNEST DALE, após ter declarado "encontrar muito pouco

2) ERNest DALE, The Great Organizers, Nova Iorque: McGraw-Hill Book Co., 1960, págs. 11 a 28. 
valor" nos princípios enunciados pelos "universalistas", muito curiosamente elaborou certas "generalizações" ou "critérios" decorrentes de seus valiosos estudos sôbre grande número de administradores . ${ }^{3}$ Ora, não seria o método comparativo de DALE, na realidade, o mesmo métcdo utilizado pelos "universalistas", que êle tanto desmerece, exceto pelo fato de que DALE recorre a um conjunto diverso de verdades básicas?

Diante da ênfase dada pela Escola Empírica ao estudo da experiência, tudo indica que a pesquisa e o pensamento oriundos de tais métodos de investigação possam vir a antecipar o dia em que se torne necessária a verificação dêsses princípios. Também é possível que os defensores dessa escola possam elaborar um conjunto de princípios mais útil do que o elaborado pela Escola do Processo Administrativo. Porém, enquanto a Escola Empírica continuar a elaborar generalizações com base em suas pesquisas - e parece necessário que isso continue a ser feito, a menos que os seus membros se proponham a trocar essas pesquisas por experiêncías sem significado e sem estrutura -, ela tenderá a ser e a fazer o mesmo que a Escola do Processo Administrativo.

\section{A Escola do Comportamento Humano (ou "Behaviorista")}

A Escola do Comportamento Humano está baseada na tese central de que, desde que administrar implica a realização de coisas por meio de pessoas, o estudo da Administração tem de arrimar-se nas relações interpessoais. A êsse moda de conceituar a Teoria Administrativa tem sido dados vários nomes: "Relações Humanas", "Liderança", "Ciências Comportamentais" etc.. Sob qualquer designação, o que importa é que essa escola introduz no campo da Teoria Administrativa "teorias novas e aproveita as teorias já existentes, os métodos e as técnicas das ciências sociais de maior importância para estudar os fenômenos

3) Idem, ibidem, págs. 11, 26 a 28 e 62 a 68. 
interpessoais e intrapessoais, cobrindo uma extensão que vai desde a dinâmica da personalidade do indivíduo até às relações entre as várias culturas". " Em outras palavras: essa escola concentra sua atenção nas "pessoas" como elementos da administração e se apóia no princípio de que as pessoas trabalham juntas, como grupos, com vistas à realização de objetivos, sendo, portanto, necessário "que as pessoas se entendam mùtuamente".

Os teóricos dessa escola são fortemente orientados para a Psicologia, em geral, e para a Psicologia Social, em particular. Suas principais preocupações são o indivíduo como um ser psicológico-social e a motivação do inłdividuo. Os membros dessa escola vão desde aquêles que consideram a Teoria Administrativa como uma parte das tarefas do administrador, um instrumento que auxilia o administrador a entender as pessoas e a obter o máximo de todos, satisfazendo as necessidades individuais e respondendo às motivações dos componentes dos grupos, até os que vêem o comportamento psicológico dos indivíduos e dos grupos como se constituísse a totalidade da administração.

Nessa escola estão aquêles que realçam as Relações Humanas como uma arte que o administrador deve compreender e praticar proveitosamente. Existem os que atentatam para o administrador como um líder e, por vêzes, equacionam administração e liderança, tendendo como conseqüência a tratar tốdas as atividades grupais como situações "administráveis". Existem, ainda, os que vêem o estudo da dinâmica grupal e das relações interpessoais como mero estudo das relações psicológicc-sociais e parecem, dessa forma, ligar o têrmo "administração" ao campo da Psicologia Social.

Que a administração tenha de lidar com o comportamento humano é inegável. Que o estudo das interações humanas, tanto no ambiente administrativo como em situações

4) R. TANnenbaum, I. R. Weschler e F. MASSARIK, Leadership and Organization, Nova Iorque: McGraw-Hill Book, Co., 1961, pág. 9. 
não administradas, constitua elemento importante e útil é questão sôbre a qual não cabe dúvida. E constituiria grave êrro considerar uma boa liderança como fator desprovido de importância para uma boa administração. Mas, dizer que o campo do comportamento humano se identifica com o campo da administração equivale a considerar o estudo do corpo humano como objeto da Cardiologia.

\section{A Escola do Sistema Social}

Estreitamente relacionada com a Escola do Comportamento Humano e freqüentemente confundida ou entrelaçada com ela, a Escola do Sistema Social inclui os pesquisadores que consideram a administração como um sistema social, isto é, um sistema de inter-relações culturais. Por vêzes, como no caso de MARch e Simon ${ }^{5}$ o sistema é limitado às organizações formais, utilizando-se o têrmo "organização" como equivalente ao têrmo "emprêsa", e não com - conceito de autoridade/atividade mais freqüentemente usado em Administração. Em outros casos a escola não distingue as organizações formais, englobando na expressão qualquer espécie de sistema de relações humanas.

Carregada de grande teor sociológico, essa escola aplica em Administração o mesmo método usado em Sociologia . Ela identifica a natureza das relações culturais de vários grupos sociais e tenta mostrá-las, habitualmente, como um sistema integrado.

O pai espiritual dessa brilhante escola talvez seja CHESTER BARNARD. ${ }^{6}$ Em busca de uma resposta às explicações fundamentais subjacentes ao processo administrativo, êsse inteligente executivo desenvolveu uma teoria de cooperação baseada nas necessidades individuais para solucionar, por meio da cooperação, as limitações biológicas, físicas e sociais do indivíduo e do ambiente. BARNARD elaborou, a

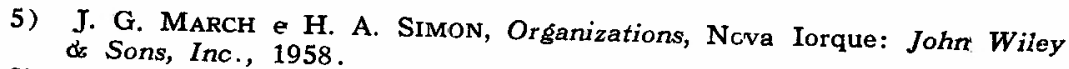

6) CHESTER BARnard, The Functions of the Executive, Cambridge, Mass.:
Harvard University Press, 1938. 
partir da totalidade dos sistemas cooperativos assim entremeados, um conjunto de inter-relações que êle define como "organização formal". Seu conceito de organização formal, diversamente do sustentado por administradores práticos, inclui qualquer sistema cooperativo no qual existam pessoas capazes de comunicar-se entre si e dispostas a agir em prol de um objetivo comum.

O conceito de sistemas cooperativos de CHESTER BARNARD permeia o trabalho de muitos contribuintes da Escola do Sistema Social. Herbert Simon, por exemplo, certa vez afirmou serem objeto da teoria da organização e constituírem a própria natureza das organizações humanas "sistemas de atividade interdependente que englobam, pelo menos, vários grupos primários habitualmente caraterizados por alto grau de orientação racional do comportamento para fins comuns conhecidos pelos participantes dêsses grupos". 'Simon e outros teóricos, ao que parece, ampliaram posteriormente êsse conceito de sistemas sociais, nêle incluindo qualquer inter-relação com objetivos delineados e cooperativos ou qualquer forma de comportamento.

Essa escola foi responsável por muitas contribuições à Teoria Administrativa dignas de menção. A identificação das emprêsas organizadas como organismos sociais sujeitos a tôdas as pressões e conflitos do ambiente cultural foi de grande auxílio para o teórico de administração e para o administrador prático. Despertou-1he, por exemplo, a consciência quanto aos fundamentos institucionais da autoridade orgânica, à influência das organizações informais e aos fatôres sociais que Wight BAKKE chamou "limites da organização". Da mesma forma, muitos dos percucien-

7) HERBERT Simon, "Comments on the Theory of Organizations", American Political Science Review, N. 4 , dezembro de 1952, pág. 1130 .

8) Wight BAKKE, Bonds of Organization, Nova Iorque: Harper and Brothers, 1950. Esses bonds (recursos) da organização para BARKE são: (a) - sistema de especificaçóes funcionais (um sistema de equipe de trabalho que tem sua origem nas especificações das tarefas e nos dispositivos de asscciação); (b) o sitema de status (uma hierarquia vertical de autoridade); (c) o sistema de comunicações; (d) o sistema de puniçóes e recompensas; e (e) o organograma (as idéias e os meior que conferem caráter e individualidade à organização ou emprêsa). 
tes conceitos de BARNARD, como o de economia de incentivos e os de sua teoria do oportunismo, foram responsáveis pela utilização das concepções sociológicas para o entendimento da realidade prática da administração.

A Sociologia Fundamental, a análise dos conceitos de comportamento social e o estudo do comportamento grupal no contexto dos sistemas sociais foram de grande valor no campo da Administração. Porém, é lícito que se pergunte se isso é, na realidade, administração. Os campos da Administração e da Sociologia seriam realmente tangentes? Ou seria a Sociologia para a Administração apenas um ingrediente importante, como a Linguagem, a Psicologia, a Fisiologia, a Matemática e outros ramos do conhecimento? Será necessário que se defina a administração em têrmos de universo de conhecimentos?

\section{A Escola da Teoria Decisória}

Adotada por um grupo de intelectuais realmente capazes e cujo número vem crescendo, a Escola da Teoria Decisória se concentra na racionalização da tomada de decisões. A seleção de uma dentre várias alternativas possíveis para o curso de uma ação ou idéia constitui o centro de interêsse dêsse grupo, para o qual o objeto de estudo é a própria decisão, as pessoas ou o grupo orgânico responsáveis pela tomada de decisões, ou a análise do processo decisório. Limitam-se alguns, muito justificàve1mente, aos aspectos econômicos da decisão; consideram outros que qualquer coisa que aconteça numa emprêsa está sujeita a sua análise; outros, ainda, estendem a teoria decisória aos aspectos psicológicos e sociológicos, ao ambiente em que as decisões são tomadas e até aos indivíduos implicados no processo decisório.

Aparentemente, a Escola da Teoria Decisória é um pro. longamento da Teoria das Escolas do Consumidor que preocupou os economistas desde os tempos de JEREMY BENTHAM, em princípios do Século XIX. Ela se originou das análises econômicas então em voga: a maximização das utilidades, as curvas de indiferença, o conceito de uti- 
lidade marginal e a análise do comportamento econômico em condições de risco e incerteza. Portanto, não deve causar surprêsa encontrar a maioria dos membros dessa escola entre os próprios economistas. Da mesma forma, não deve surpreender que o conteúdo das teorias postuladas por essa escola esteja fortemente orientado em direção à construção de modelos e matrizes matemáticos .

A Escola da Teoria Decisória tendeu a expandir seus horizontes para além do processo de avaliação de alternativas. Para muitos êsse tópico constitui apenas um ponto de apoio para examinar tốda uma gama de atividades humanas, bem como a natureza da estrutura orgânica, as reações sociais e psicológicas de indivíduos e grupos, e o desenvolvimento de informações básicas no que se refere a objetivos, sistemas de comunicações e incentivos. Como seria de esperar, quando os teóricos da decisão estudam a área pequena mas vital da tomada de decisão, êles são dirigidos por essa chave-mestra que considera a administração como o campo total das operações da emprêsa e de seu meio ambiente. O resultado é que a Teoria Decisória se transforma numa ampla concepção da emprêsa como sistema social, sem mais se limitar ao processo decisório.

Alguns acreditam que, sendo a administração caraterizada por uma concentração nas decisões, o desenvolvimento da Teoria Administrativa no futuro tenderá a utilizar a decisão como ponto central e que o restante será mera ramificação dêsse ponto central. Isso poderá vir a ocorrer e com tôda a certeza o estudo da decisão, do processo decisório e do tomador de decisões poderá estender-se a todo o campo da administracão. Todavia, pode-se indagar se êsse tratamento não seria aplicável, também, a tôda a esfera do conhecimento humano, porque, como a maioria dos teóricos reconhecem, o problema da escolha não é apenas individual, mas também orgânico, e a maior parte do que tem sido dito como constituindo pura teoria decisória pode ser aplicado à existência e ao pensamento de um ROBINSON CRUSOE. 


\section{A Escola Matemática}

Se bem que os métodos matemáticos possam ser usados por qualquer escola de Teoria Administrativa - e, na verdade, êsse tem sido o caso —, decidi-me a agrupar sob a rubrica "Escola Matemática" os teóricos que vêem a administração conno um sistema de modelos e processos matemáticos. Talvez o grupo mais amplamente conhecido - que arbitràriamente rotulo de "matemático" - seja o dos "pesquisadores operacionais" ou analistas de operações, que, por vêzes, nretensiosamente se ungem a si mesmos com o pomposo nome de "cientistas da administração". Afirma êsse grupo que, se a administração, a organização, o planejamento e a tomada de decisões constituem processos lógicos, êles poderão ser expressos por símbolos e por relações matemáticas. O recurso principal dessa escola é o modêlo: é por meio dêle que o problema se expressa nas suas relações básicas e em têrmos de objetivos e propósitos selecionados .

Não resta dúvida quanto à grande utilidade da Matemática em qualquer campo de investigação. Ela obriga o pesquisador a uma definição do problema ou da área problemática, permite o emprêgo conveniente de símbolos para dados desconhecidos, adota uma metodologia lógica, desenvolvida no decurso de longos anos de aplicação científica e de abstração, e é um instrumento poderoso para solucionar ou simplificar fenômenos complexos.

Mas, é bastante difícil considerar a Matemática como uma escola distinta de Teoria Administrativa, da mesma forma que seria difícil considerar uma escola matemática nas várias disciplinas que a utilizam, como a Física, a Química, a Engenharia ou a Medicina. Refiro-me aqui a uma Escola Matemática porque percebo ter-se desenvolvido uma espécie de culto entre os analistas matemáticos que resultou numa incorporação da administração na sua esfera de pensamento.

Ao afirmar que a Matemática é instrumento e não escola, não pretendo subestimar sua utilidade na prática da admi- 
nistração. Trazendo ao imenso e complexo campo da Administração os instrumentos e os métodos das ciências exatas, os matemáticos já lhe deram inestimável contribuição no sentido de ordenar-lhe o processo intelectual. Êles forçaram muitas pessoas envolvidas na administração a focalizar vários problemas de maneira mais clara, obrigaram intelectuais e administradores práticos a estabelecer objetivos e critérios de eficiência, contribuíram para que a área da administração se transformasse num sistema lógico de relações e fizeram com que as pessoas envolvidas na administraçăo revissem e eventualmente reorganizassem fontes e sistemas de informações a fim de que se pudesse dar aos problemas um significado matemático. Mas, apesar de tão grande contribuicão, máxime na esfera do planejamento, seria insensato afirmar que Matemática é sinônimo de Teoria Administrativa, da mesma forma que não se poderia afirmar que Matemática é sinônimo de Astronomia.

Resumidas as várias escolas de Teoria Administrativa, torna-se claro que êsses vários cultos intelectuais não estão levando à descoberta de inferências diferentes, a partir dos ambientes cultural e físico que nos rodeiam. Porque, então, existem tantas diferenças entre as várias escolas? Porque tanta luta, especialmente entre os nossos acadêmicos, que procuram obter um lugar ao sol simplesmente por negarem as afirmações dos outros? Da mesma forma que as diferentes seitas da religião cristã, por vêzes tão litigiosas, tôdas as escolas da Teoria Administrativa têm, essencialmente, os mesmos objetivos e tratam, bàsicamente, com a mesma realidade.

Embora haja muitas fontes de confusão mental no emaranhado da Teoria Administrativa, creio que as principais são as que a seguir serão mencionadas. 


\section{A Confusão Semântica}

Quando homens inteligentes tratam de problemas básicos, é comum que parte das divergências resida no significado das palavras. $O$ problema semântico é particularmente difícil no campo da administração. A própria palavra "administração" apresenta problemas quanto ao seu significado. A maioria concordaria em que administrar significa realizar coisas com e por meio de pessoas. Mas, através da organização formal, ou por qualquer atividade grupal? Administrar é liderar, governar ou ensinar?

Talvez a maior confusão semântica resida no uso da palavra "organização". A maioria dos partidários da Escola do Processo Administrativo usam o têrmo para definir a estrutura atividade/autoridade de uma emprêsa e, certamente, grande parte dos administradores práticos acreditam que estão "organizando" quando estabelecem um conjunto de grupos de autoridade e de relações de autoridade. Nesse caso organização representa a estrutura formal dentro de uma emprêsa, que cria o ambiente no qual as pessoas desempenham suas funções. Existe mesmo grande número de teóricos que entendem a organização como a soma total das relações humanas em qualquer grupo de atividade. Dessa forma, êles parecem consid rar o têrmo "organização" sinônimo de estrutura social. $\mathrm{E}$ existem, ainda, os que dizem "organização" para dizer "emprêsa".

Se o significado da palavra "organização" não puder ser esclarecido e o uso do têrmo não puder ser padronizado convencionalmente pelos vários teóricos de Administração, o entendimento e a crítica não poderão estar fundamentados nessa diferença. Não creio que MARCh e Simon sejam precisos, por exemplo, ao criticar as teorias de organização da Escola do Processo Administrativo - que êles chamam de "universalista" - pelo fato de não considerarem a função administrativa de planejamento como parte da função organizadora, uma vez que elas decidiram tratar dela separadamente. Nem tampouco devem ser 
criticados aquêles que decidiram tratar isoladamente das funções de treinamento, seleção e direção ou liderança de pessoas como sendo de assessoria, ou os que dão ênfase à função de direção por causa de uma "tendência para considerar o empregado como um instrumento inerte" ou "mais como uma constante do que como uma variável"." Tais acusações, porque se apóiam em premissas falsas, são evidentemente errôneas.

Outras confusões semânticas poderiam ser mencionadas . Por alguns a tomada de decisão é olhada como um processo de escolha entre várias alternativas; para outros ela constitui a totalidade da tarefa administrativa e a totalidade do ambiente. Freqüentemente são usados como sinônimos os têrmos "administração" e "liderança", palavras que outros separam analiticamente. A palavra "comunicações" poderá significar tudo, desde um relatório escrito ou oral até um vasto sistema de relações formais e informais. Relações Humanas para alguns implica numa manipulação psiquiátrica das pessoas, para outros no estudo e a na arte de entender as pessoas e as inter-relações pessoais.

Disparidade na Acepção de Administração como Conjunto de Conhecimentos

Como já foi indicado na discussão a respeito da confusão semântica, "administração" está longe de ter um significado único, embora a maioria esteja de acôrdo em que ela envolve, pelo menos, a realização de coisas com e por meio de pessoas. Quer isso dizer, porém, que ela trate de tôdas as relações humanas? Um vendedor-ambulante é um administrador? O pai é um administrador? O líder de uma multidão é um administrador? Identifica-se o campo da administração com o campo coberto conjuntamente pela Psicologia e pela Sociologia? Administração é o mesmo que um sistema completo de relações sociais?

9) J. G. MARCH — H. A. Simon, op. cit., págs. 29 a 33. 
Reconheço que linhas precisas não possam ser traçadas em Administração, pois igual impossibilidade existe em Medicina e em Engenharia. Todavia, há certamente a possibilidade de estabelecer uma distinção mais perfeita do que a existente atualmente. $O$ qưle não se pode esperar é que a Teoria Administrativa seja vista como cientìficamente útil para um administrador prático, quando as "autoridades" chamam de "administração" tudo o que existe sôbre a face da terra.

\section{As Hipóteses "a priori"}

A confusão na Teoria Administrativa também tem sido aumentada pela tendência, encontrada entre os novatos no campo, para eliminar importantes observações e análises realizadas no passado, sob a alegação de que elas seriam. apriorísticas em sua natureza. Essa é uma acusação muito encontradiça entre os que desejam invalidar a obra de FAyol, MoONEy, Brown, URwICK, Gulick e outros que são rotulados de "universalistas". Supor que as experiências elaboradas por homens como êsses constituem formas apriorísticas de raciocínio é esquecer que a experiência administrativa é fundamentalmente empírica. Embora as conclusões das experiências e percepções de tarimbados práticos da arte de administrar não sejam infalíveis, elas não deixam de ser representativas, pois representam uma experiência vivida, que é indiscutìvelmente "real", e não o resultado de laborações realizadas numa "tôrre de marfim”. Ninguém poderá negar — e eu estou absolutamente seguro a respeito - que o teste final da "veracidade" de uma teoria administrativa tem de ser a prática e que a prática e o estudo da administração terão de desenvolver-se a partir da realidade.

\section{O Mal-Entendido a respeito dos "Principios"}

Aquêles que acham que podem adquirir status e uma "bela ficha" simplesmente por proporem algum tratamento ou noção particular amiúde se deleitam em refutar qualquer coisa que recenda a princípios de administração. Alguns 
têm-se referido aos princípios como "óbvios", esquecendo que o óbvio é também um truísmo e que um conceito não se torna válido simplesmente por ser familiar. (Como ROBERT FROST afirmou, "A maior parte das mudanças que pensamos encontrar na vida são meras verdades que entram e saem da moda".) Outros refutam os princípios de FAYOL e de outros práticos de administração, simplesmente para delinear generalizações aparentemente diversas nos seus estudos de Administração; mas, muitas das generalizações descobertas dessa forma são, com freqüência, as mesmas leis fundamentais, com enunciados diferentes, que certos "universalistas", violentamente criticados, já haviam descoberto.

Um dos lances favoritos no "jôgo" da Teoria Administrativa é recusar todo um conjunto de princípios com base em um único princípio que o observador julgue não estar pràticamente fundamentado. Dessa maneira, muitos críticos dos "universalistas" referem-se aos casos bem conhecidos de dupla subordinação, encontrados na prática empresária, chegando por êsse caminho à errônea conclusão de que não há substância no princípio de unidade de comando. Mas, isso não prova que não exista um gravame de custo para a emprêsa que adote práticas administrativas dispersivas ou não leve em consideração o princípio da unidade de comando. Não prova, tampouco, que deixem de existir outras vantagens que compensem $o$ custo de adotar técnicas dispersivas, como sucede frequientemente em estabelecimentos organizados com distribuição funcional de autoridade.

Talvez o estereótipo mais utilizado por aquêles que questionam a validade de todos os princípios por referência a uma base comum seja o dos mal-entendidos a respeito do princípio de "amplitude administrativa" (span of management, span of control). A fonte de autoridade habitualmente citada pelos que tentam a invalidação do referido princípio é Sir IAN HAMILTON, que nunca pretendeu estabelecer um princípio universal, mas simplesmente desejou fazer uma observação pessoal num livro de re- 
flexões sôbre suas experiências no Exército, onde afirmou casualmente que êle julgava aconselhável limitar o número de seus subordinados entre três e seis. Nenhum universalista moderno se apóia em tal afirmação. Na verdade, poucos estarão dispostos a estabelecer um limite numérico universal e absoluto (nem mesmo poderiam fa$z \hat{e}-10)$. Considerando-se que Sir Ian Hamilton não era um teórico em Administração e que nunca pretendeu sê-lo, tenhamos a esperança de que o fantasma de sua observação inocente mereça o eterno repouso!

No que diz respeito àqueles que julgam que o reconhecimento de verdades fundamentais ou de generalizações possa ser útil, no estudo e no diagnóstico dos problemas de administração, e que sabem, por experiência administrativa, que tais verdades ou princípios são de uso extremamente valioso, há a tendência de alguns pesquisadores no sentido de tentarem provar coisas errôneas, seja poṛ meio de falsas afirmações, seja por meio de indevida aplicação de princípios. Caso clássico de mal-entendido e má aplicação é o interessante livro de CHRYs ARGYRIS, Personality and Organization. ${ }^{10}$ Esse autor, que nesse livro e em outras obras deu muitas contribuições valiosas à Administração, conclui que "os princípios da organização formal encerram exigências para com indivíduos relativamente sadios, que são incongruentes com suas necessidades", e que "a frustração, o conflito, o fracasso e as. perspectivas a curto prazo são previsíveis como resultados dessa incongruência básica". ${ }^{11}$ Essa chocante conclusão - que representa o oposto do que a boa organização formal, baseada em sólidos princípios de organização, deve causar - é explicável quando se observa que dos quatro "princípios" citados por ARGYRIS um não é princípio de organização, mas princípio econômico de especialização, e os outros três estão citados errôneamente. ${ }^{12}$ Com

10) Chrys ARgYris, Personality and Organization, Nova Iorque: Harper and Brothers, 1957.

11) Idem, ibidem, pág. 74

12) Idem, ibidem, págs. 58 a 66. 
base em tal postulado, e sem tentar reconhecer, correta ou incorretamente, nenhuma outra organização e nenhum outro princípio de administração, ARGYRIS simplesmente demonstrou que princípios errados aplicados indevidamente conduzem à frustração. E qualquer administrador sabe que isso é absolutamente verdadeiro!

Incapacidade ou Má Vontade para um Acôrdo entre os Teóricos de Administração

O que foi dito acima nos leva à conclusão de que grande parte da confusão reinante na Teoria Administrativa é causada pela má vontade ou pela incapacidade de entendimento mútuo por parte dos teóricos em Administração. Duvidando, porém, que a causa seja a incapacidade, porque suponho que quem se interêsse por Teoria Administrativa seja capaz de compreender pelo menos seus princípios gerais e os sistemas adotados pelas várias "escolas", só me resta concluir que o obstáculo para o entendimento seja a má vontade.

E provável que essa má vontade tenha suas origens nas "barreiras" profissionais que se desenvolvem no aprendizado das várias disciplinas, ou no mêdo de que alguém ou de que alguma descoberta comprometa o status profissional ou acadêmico, ou, ainda, no mêdo de obsolescência profissional ou acadêmica. Mas, qualquer que seja a causa, parece-me que essas barreiras não serão demolidas até que se compreenda que elas "existem", até que todos os cultistas estejam dispostos a considerar a validade e o conteúdo das outras escolas e até que, através da troca de idéias e de entendimentos, alguma ordem possa ser criada a partir do caos atual.

\section{DESBRAVANDO A "FLORESTA"}

$E$ de grande importância que se tomem medidas para desbravar a "floresta" da Teoria Administrativa. Talvez seja muito cedo e para que isso ocorra sejamos obrigados a esperar alguns anos, que decorrerão entre tentati- 
vas e buscas entremeadas por um sem número de problemas semânticos, golpes e contragolpes. Mas, por se tratar de uma área tão importante para a sociedade, onde os vários erros de uma administração desprovida de fundamentos científicos podem ser custosos, é de esperar que essa demora não se prolongue por muito tempo.

Parece-me que algumas providências podem começar a ser tomadas no sentido de afastar as fontes mais importantes da confusão. Façamos, a propósito, algumas considerações.

Necessidade de definir um conjunto de conhecimentos - Certamente, se não se quer ver um campo do conhecimento "paralisado" num lamaçal de mal-entendidos, a primeira necessidade é definir o "objeto de conhecimento". Esse "campo", claro está, não pode ser delimitado minuciosa e inflexìvelmente, mas sim ao longo de linhas que situem o seu conteúdo específico. Pelo fato de a administração ser realidade, vida e prática, minhas sugestões seriam no sentido de que o objeto fôsse definido à luz do quadro de referência do prático de administração capaz e lúcido. Uma ciência sem relação com a prática ou com a arte a que ela se propõe servir não poderá ser eficaz.

Levando em consideração que os estudos das administrações de várias emprêsas, em vários países e em vários niveis, levados a cabo por várias pessoas, entre as quais me incluo, não são nem representativos, nem adequados, cheguei à conclusão de que Administração é a arte de realizar coisas com e por meios de pessoas em grupos formalmente organizados; a arte de criar um ambiente nesses grupos, onde as pessoas possam agir individualmente mas cooperando para a consecução dos objetivos grupais; a arte de afastar os obstáculos a tal consecução; a arte de otimizar a eficiência na consecução eficaz dos objetivos. Se êsse tipo de definição do "campo" não fôr satisfatório, sugerirei, como forma de acôrdo, que a área seja pelo menos definida com a finalidade de refletir o campo do administrador prático e que posteriores pesquisas e estudos da prática sejam feitos com vistas a êsse objetivo. 
Ao definir o campo, parece-me também imperativo estabelecer alguns limites com relação à análise e à pesquisa. Se designarmos os universos cultural, físico e biológico como sendo o campo da administração, não pc'deremos realizar grandes progressos, da mesma forma que a Química ou a Geologia teriam estacionado, enquanto ciências, se não tivessem delimitado áreas específicas de estudo. Se tivessem optado por um estudo da totalidade do conhecimento, por certo não se teriam constituído ciências.

Ao definir um campo de conhecimento, deve-se também cuidar que se faça distinção entre instrumentos e conteúdo. Conseqüentemente, a Matemática, a Pesquisa Operacional, a Contabilidade, a Teoria Econômica, a Sociometria e a Psicologia - para mencionar apenas alguns casos constituem instrumentos importantes para a Administração, mas não são, em si mesmas, parte do conteúdo do campo. Isso não quer dizer que elas sejam destituídas de importância ou que o administrador prático não deva manter essas disciplinas sempre à sua disposição, nem significa que tais disciplinas não possam servir de meios para fazer regredir os limites do campo de conhecimento administrativo. Significa apenas que elas não devem ser confundidas com o conteúdo básico do campo da Administração.

Claro está que um estudo frutífero não deve prescindir das disciplinas subjacentes à Administração. Com tôda a certeza, o conhecimento da Sociologia, dos sistemas sociais, da Economia, da Ciência Política, da Matemática e de outras áreas, quando dirigido para a finalidade de contribuir para o campo da Administração, deve ser objeto de continuidade e de encorajamento. $E$ descobertas importantes nesses e noutros campos do conhecimento podem. lançar luz sôbre os conceitos e transformá-los no campo da Administração. Isso certamente já aconteceu em outras ciências e em tôdas as demais artes baseadas em ciências importantes.

Integração da Administração e de outras disciplinas de importância - Se o reconhecimento do conteúdo adequa- 
do do campo da Administração já tivesse sido feito, creio que a atual luta de mal-entendidos tenderia a desaparecer. A Administração seria olhada como disciplina específica e outras disciplinas seriam consideradas importantes bases para a Administração. Nessas circunstâncias as disciplinas subjacentes e inter-relacionadas seriam consideradas benvindas pelas escolas de administração pública e de emprêsas, bem como pelos administradores práticos, como sendo associadas leais e prestativas. $\mathrm{E}$ a integração da Administração e das outras disciplinas não seria tão difícil.

Esclarecimento da terminologia administrativa - A necessidade de esclarecimento e de uniformização da terminologia administrativa seria, em boa parte, resultado da delimitação do objeto da Administração e de sua definição como campo de conhecimento. Porém, mesmo em tais circunstâncias, os problemas terminológicos exigiriam atenção especial. Não são muitas as situações em que a terminologia seja por si só suficiente para causar embaraços.

Aqui também seria sensato adotar a terminologia diss administradores práticos, a menos que as palavras sejam por êstes usadas de forma tão inexata que exija esclarecimento especial. Pelo menos, não deveríamos complicar ainda mais um campo já bastante complexo, pelo desenvolvimento de um jargão acadêmico ou científico que construiria outra barreira lingüística entre o teórico e o administrador prático.

Talvez o mais prático seja estabelecer uma comissão representativa de sociedades acadêmicas e associações de administradores diretamente envolvidas nesses problemas terminológicos. Tal solução parece bastante viável e de implantação não muito difícil. E mesmo que o fôsse, os resultados compensariam os esforços.

- Boa-vontade para elaborar e testar os fundamentos - Certamente, o teste da maturidade e da utilidade de uma ciência é a acuidade e a validade dos princípios que 
lhe servem de base. Nenhuma ciência atualmente considerada madura se iniciou com uma completa afirmação de princípios irretorquivelmente válidos. Mesmo as ciências mais velhas, como a Física, continua revendo os seus princípios e leis fundamentais, e descobrindo novos princípios. Na verdade, qualquer ciência se desenvolve e tem utilidade durante séculos com base em generalizações, leis e princípios.

Uma das provas da inferioridade das Ciências Sociais de fácil compreensão é a de serem, reconhecidamente, ciências inexatas. Por outro lado, mesmo as chamadas "ciências exatas" estão sujeitas a grande margem de inexatidão, possuem princípios não inteiramente demonstráveis e recorrem à arte na elaboração de sistemas e componentes práticos. A atitude derrotista tão freqüentemente encontrada entre as Ciências Sociais, das quais a Administração é parte, não dá a importância devida ao fato de que a Administração poderá ser explicada, poderá ter a sua prática melhorada e tornar os objetivos de suas pesquisas mais significativos se tentativas forem feitas para uma elaboração perceptiva da experiência por meio da descoberta de princípios (ou generalizações) e pela sua ordenação num contexto lógico. Como dois cientistas recentente afirmaram a êsse respeito, "A razão para essa maneira derrotista de encarar as Ciências Sociais pode ser encontrada no mau entendimento básico da natureza da busca científica. O que importa não é que as inexatidões nos procedimentos e a capacidade de previsão da ciência possam ser eventualmente removidos. [...] 0 que importa é a objetividade, isto é, a inter-subjetividade das descobertas, independentemente do julgamento intuitivo de qualquer pessoa, que distingue a ciência das opiniões intuitivas, por mais brilhantes que estas possam ser. [...] Porém, uma vez que uma idéia nova tenha sido elaborada, não importa quão intuitivo seja o seu fundamento, ela terá de enfrentar um teste ou uma confirmação objetiva. E é a êsse padrão crucial de objetividade científica, mais do que a qualquer outro critério aparente de 
exatidão, que as Ciências Sociais têm de se conformar".13 Tentando um esclarecimento da Teoria Administrativa, não poderia deixar de lembrar alguns outros critérios:

- A Teoria terá de lidar com uma área de conhecimento e inquirição que seja tratável. Não se fizeram grandes avanços no conhecimento enquanto o homem se limitou a contemplar o Universo como um todo.

- A Teoria terá de ser útil no melhoramento da prática administrativa, não deixando de dar a devida atenção à pessoa do administrador e às suas tarefas.

- A Teoria não pode perder-se em questões de terminologia, particularmente em jargões inúteis e ininteligíveis pelo administrador prático.

- A Teoria deve fornecer uma diretriz e conferir eficácia para a pesquisa e para o ensino da Administração. E, finalmente,

- A Teoria Administrativa deve reconhecer que é parte de um universo maior de conhecimento e de teoria.

13) O. HeLmer e N. Rescher, On the Epistemology of the Inexact Sciences, Santa Mônica, Califórnia: The Rand Corporation, P-1513, 1958, págs. 4 e 5 . 